\title{
Las instituciones científicas en la Argentina de la última dictadura cívico-militar (1976-1983)
}

\author{
The scientific institutions in Argentina during the last civilian-military \\ dictatorship (1976-1983)
}

DIEGO HURTADO

Universidad Nacional de San Martín | UNSAM, Argentina

CECILIA GÁRGANO

Universidad Nacional de San Martín | UNSAM, Argentina

RESUMEN Los estudios centrados en la última dictadura en Argentina (1976-1983) se han constituido en un fecundo campo de estudios. En ellos, la intervención militar en ámbitos de producción de conocimiento científico y tecnológico constituye una temática poco explorada. Este artículo se propone contribuir a este análisis, a partir de la indagación de tres de las principales instituciones del complejo científico-tecnológico. Con el objetivo de analizar i) experiencias en las distintas comunidades científicas; ii) introducción de mecanismos represivos; y iii) agendas de investigación de los organismos, se reconstruyen las trayectorias institucionales en diálogo con transformaciones socio-económicas y políticas del período.

Palabras clave instituciones - ciencia - tecnología - dictadura - agro-energía nuclear.

\begin{abstract}
Studies centered on the last dictatorship in Argentina (1976-1983) have become a fertile field of investigation. Among the possibilities, military intervention in areas of production of scientific and technological knowledge has been scarcely explored. This article aims to contribute to this analysis, based on the investigation of three of the main institutions of the scientific-technological complex. With the intention of analyzing the experiences of different scientific communities, the introduction of repressive mechanisms, and the research agendas of the organizations, institutional trajectories are examined in dialogue with the socio-economic and political transformations of the period.
\end{abstract}

Keywords institutions - science - technology - dictatorship - agro-nuclear energy.

\section{Introducción}

La sucesión de golpes militares producidos en forma casi sincrónica en América Latina ha sido estudiada en forma creciente desde diversos ángulos. A diferencia de otras temáticas, las intervenciones militares en las instituciones de investigación científica y desarrollo tecnológico y su impacto en las agendas de trabajo y en las trayectorias institucionales han sido ejes poco abordados. Lo sucedido en el complejo científico-tecnológico argentino durante la última dictadura militar (1976-1983) aparece como un área de vacancia, sobre la que algunos estudios han indagado¹. Este 
artículo se propone contribuir a esta línea de investigación, a partir del análisis comparativo de las trayectorias de las principales instituciones argentinas de Ciencia y Tecnología (CyT).

Igual que los gobiernos de facto brasileño (1964-1985) y uruguayo (1973-1985), caracterizados como "dictaduras institucionales" de las Fuerzas Armadas, la última dictadura argentina se asumió a sí misma como permanente, tuvo pretensiones refundacionales y, en términos ideológicos, estuvo guiada por la Doctrina de la Seguridad Nacional.? La reconfiguración de las fracciones de poder económico a partir de alianzas entre grupos empresarios y funcionarios de la dictadura, en conjunción con las políticas de disciplinamiento social y de terrorismo de Estado, alteró tanto el mapa de

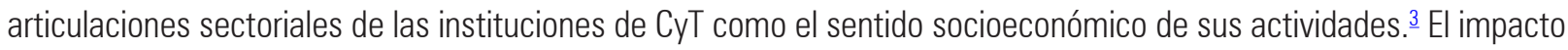
no fue simétrico, ni para las instituciones, ni para las diversas líneas de investigación.

¿Cómo experimentaron estos espacios la reconfiguración económica, el disciplinamiento social, la continuidad y discontinuidad de sus líneas de investigación? Para responder estos interrogantes, exploraremos en profundidad algunas de las principales comunidades científico-tecnológicas. Las especificidades sectoriales y las distintas modalidades de intervención motivan la selección de tres de las instituciones de CyT más relevantes de Argentina: la Comisión Nacional de Energía Atómica (CNEA), el Instituto Nacional de Tecnología Agropecuaria (INTA) y el Consejo Nacional de Investigaciones Científicas y Técnicas (CONICET). En cada una de las trayectorias de estas instituciones nos interesa analizar: (i) ¿qué objetivos - explícitos o implícitos - se propusieron las políticas represivas que el autodenominado "Proceso de Reorganización Nacional" desplegó sobre la población de científicos y tecnólogos?; (ii) ¿qué consecuencias produjeron estas políticas sobre las trayectorias institucionales y cómo se correlacionan en el corto y en el mediano plazo con las políticas sectoriales - nuclear, agropecuaria y de investigación académica - que guiaban a cada una de las instituciones analizadas?; (iii) ¿cómo impactaron estas transformaciones en las modalidades de enraizamiento económico y social?; y (iv) ¿cuáles fueron las consecuencias de largo plazo?

La hipótesis que sostenemos son: (i) la introducción de mecanismos represivos en las instituciones de investigación y desarrollo tecnológico durante la última dictadura estuvo asociada a una resignificación de su roles institucionales y a una reestructuración de contenidos y destinatarios de sus agendas de trabajo; (ii) los principales organismos de CYT (INTA, CNEA y CONICET) modificaron durante este período sus modalidades de enraizamiento social y económico; (iii) estas transformaciones fueron resultado y, a la vez, insumos para la reorientación de las políticas sectoriales y del patrón de acumulación local.

El primer apartado analiza la trayectoria institucional del INTA, explorando continuidades y rupturas en sus líneas de acción desde su creación hasta su intervención militar, producida entre 1976 y 1983. En un sentido similar, el segundo analiza la trayectoria de la CNEA. El tercer apartado aborda el caso del CONICET. Finalmente, en las conclusiones se puntualizan los resultados obtenidos y se sugieren nuevos interrogantes.

\section{El INTA: disputas en el agro argentino}

El INTA fue creado en 1956, en un marco de crisis económica asociada al agotamiento de los saldos agrícolas exportables, situación que demandaba tecnificar el espacio rural. Políticamente, el contexto nacional se caracterizaba por el avance de la dictadura autodenominada "Revolución Libertadora", que en 1955 había derrocado al presidente Juan Domingo Perón. El drecreto-ley de creación del organismo reprodujo de manera implícita una contradicción propia de la estructura económica del agro argentino, que se desplegaría dentro del INTA en las décadas siguientes. En ella se afirmaba que uno de sus objetivos sería "incrementar la producción agropecuaria", que a su vez debía "la elevación del nivel de la vida social y económica de la familia campesina". ㄴ La trayectoria posterior del organismo demostraría

que la estructura de propiedad de la tierra fue un obstáculo que imposibilitó la convergencia entre políticas de apoyo a los procesos de "tecnificación" que mejorasen la productividad del sector, y políticas de investigación y extensión rural orientadas a resolver las problemáticas socioeconómicas de la denominada "familia rural". 
Desde su origen, el interlocutor típico del INTA fue el "chacarero" medio, seguido por los productores más capitalizados. Ni asalariados rurales, ni campesinos o productores de subsistencia estuvieron dentro de las directrices institucionales. Sin embargo, una de las interpretaciones de esta ley, que iba a ser defendida por buena parte del personal del INTA durante la primera mitad de la década de 1970, cuestionaba esta orientación, señalando que a mediados de la década de 1950 las tecnologías "estaban en manos casi exclusivamente de los grandes terratenientes o grandes capitales industriales-agropecuarios" y que el INTA debería ponerlas también "al servicio de los pequeños y medianos productores y de todas las regiones". $\underline{5}$

Esta posición, que hacía foco en la familia rural, el pequeño productor y la densa trama de especificidades de las economías regionales como principales objetos de intervención, desafiaba la orientación tradicionalmente hegemónica dentro del INTA, de enfoque "productivista", que ponía el foco en el aumento de los niveles de rendimiento y producción en desconexión con las problemáticas socio-económicas, favoreciendo en gran medida a los agricultores más capitalizados. Los debates centrados en para qué y para quiénes tenía que trabajar el INTA se desplegaron a lo largo de la década de 1970, en un marco histórico local y regional de intensa movilización y conflicto social. Fueron, precisamente, estas disputas, heterogéneas y de alcances limitados, las que quedaron truncadas una vez producido el golpe de Estado en 1976.

Las tensiones que se estaban desplegando al interior del INTA implicaban poner en discusión sus propios orígenes y sentidos fundacionales. Primer organismo en su tipo de toda América Latina, su creación fue parte de un proceso más amplio, que en pocos años avanzó creando instituciones de investigación orientadas al medio rural en distintos países de la región. $\underline{6}$ En este proceso, el peso de las agencias internacionales fue sumamente relevante, tanto por los aportes de recursos materiales para la organización de diversos programas, como por la propagación de diversos enfoques teóricos que impregnaron el abordaje de la cuestión rural. Esta situación estuvo estrechamente vinculada a la difusión de los esquemas teóricos e insumos productivos propios de la revolución verde. Estos planteos funcionaron como marco ideológico y como referencia para los planes de desarrollo rural, que acompañaron y viabilizaron las transformaciones en las pautas de producción y consumo agrícolas. $\stackrel{?}{-}$ Tomando como modelos organizacionales al Institut National de la Recherche Agronomique (INRA) francés y al sistema de extensión rural estadounidense, la puesta en marcha del INTA tuvo como primer desafío la implementación de estos nuevos modelos, productivos y teóricos, en un escenario geográfico y socio-económico completamente diferente. A diferencia de sus pares internacionales, abocados por completo a la investigación, el INTA concibió un esquema institucional en el que la investigación agropecuaria y la extensión rural dirigida al contacto directo con los productores se desarrollasen en conjunto. Para eso, desde la década de 1960 multiplicó a lo largo del territorio nacional la cantidad de estaciones experimentales agronómicas y agencias de extensión rural, heredadas inicialmente del Ministerio de Agricultura. ${ }^{-}$El reconocimiento social del INTA comenzó así a crecer a base de su presencia territorial, lo que a su vez fomentó que empezara a cuestionarse lentamente la idea, heredada de los teóricos de la modernización agrícola, del campo como lugar del atraso y de sus habitantes como elementos arcaicos a los que había que transformar en agentes económicos racionales.

En cuanto al órgano máximo de gobierno, fue establecido un Consejo Directivo integrado por representantes del Poder Ejecutivo, las universidades y el sector privado. Esta situación se vinculaba, por un lado, al carácter autárquico del organismo, que le permitía disponer libremente de un fondo compuesto por el 1,5\% ad valorem de las exportaciones agropecuarias. Por otro, revelaba la importancia en la trayectoria institucional del INTA de los dirigentes de las principales corporaciones agropecuarias, actores de peso en la vida política y económica nacional. La estructura institucional fue completada con la anexión de un Centro Nacional de Investigaciones Agropecuarias (CNIA), ubicado en la zona oeste de la provincia de Buenos Aires, donde se concentró la ciencia básica y las investigaciones orientadas a clima y suelos.

Allí también se radicaron equipos de investigación en economía agraria, área de escaso desarrollo el país, y tuvo lugar una experiencia pionera en formación superior, la Escuela para Graduados en Ciencias Agropecuarias (EPG), que funcionó en el predio del CNIA desde 1967. ․ En este ámbito, en especial en lo referente a economía agraria, inicialmente dominó un enfoque neoclásico orientado a la administración rural. En pocos años, en la EPG se fueron introduciendo corrientes latinoamericanas de pensamiento económico, especialmente cepalinas y estructuralistas. En 1974, alumnos 
y docentes tomaron la Escuela con el reclamo de un cambio de organización y de "trabajar otras problemáticas". La toma fue exitosa y, como resultado, se introdujeron modificaciones en el plantel docente, los contenidos de las asignaturas y la dirección de la Escuela, que dejó de depender del IICA para responder al INTA. ${ }^{10}$ En este sentido, mientras que la actividad gremial del personal había crecido en intensidad, también se habían generado cuestionamientos a los enfoques y contenidos de la investigación y de la extensión rural. La renovación no duró mucho, en mayo de 1975, en medio de una profunda crisis política y económica a nivel nacional acompañada por una fuerte escalada represiva, el INTA fue intervenido mediante un decreto del Poder Ejecutivo. Menos de un año después, el 24 de marzo de 1976, se produjo un nuevo golpe de Estado, de características inéditas en la historia argentina, que se extendería hasta 1983. ¿Cuál fue, entonces, la trayectoria del INTA durante la dictadura?

\section{INTA en dictadura}

Al igual que el resto de las instituciones de CyT, el organismo fue intervenido militarmente. Con un alto nivel de violencia, el 29 de marzo, se realizó un operativo militar en el CNIA, en Castelar, provincia de Buenos Aires. Parte del personal fue conducido al comedor e interrogado y algunos, incluso, sometidos a simulacros de fusilamiento. Según testimonios posteriores, alrededor de doscientas personas fueron detenidas y muchas permanecieron por sesenta días en una comisaría de la zona. $\frac{11}{}$ En simultáneo, la estación experimental de Famaillá (provincia de Tucumán) fue ocupada por personal militar. El 31 de marzo, el interventor designado al frente del INTA, el capitán de Fragata Alberto Rafael Heredia, firmó una resolución enmarcada en la ley 21.260 que autorizaba la prescindibilidad de personal de la administración pública por "razones de seguridad". La resolución dejó cesantes a 153 personas en las distintas sedes del país, que llegarían a 194 al final de 1976, y a 794 para 1981.12

En un memorándum al embajador de EEUU en Argentina con fecha 8 de abril, su agregado de agricultura, James Rudbeck, relataba un encuentro con un funcionario argentino de la cartera agropecuaria, Lucio Reca. $\frac{13}{3}$ Según este documento, Reca habló de trabajadores, delegados sindicales y profesionales de la sede del INTA Castelar que habían sido exonerados como parte de la purga de "los así llamados 'subversivos'". Mencionaba a siete exonerados de la "Sección de Estudios Económicos de Agricultura", "que fueron levantados de sus escritorios por las fuerzas de seguridad y llevados a prisión en un colectivo". Tres de los arrestados - Martín Piñeiro, Eduardo Trigo y Raúl Fiorentino - "habían recibido entrenamiento en EEUU bajo el patrocinio de la Fundación Ford". Como la Fundación había firmado recientemente otro acuerdo de apoyo financiero con estos profesionales, Rudbeck quería información sobre el "carácter de todos estos individuos". 14 Es decir, quería elementos de juicio para decidir si la Fundación Ford podía salir en su defensa. A diferencia de lo que sucedía en la prensa local, ésta y otras situaciones eran mencionadas en medios científicos internacionales..$^{15}$ Las acciones represivas desplegadas en el INTA no involucraron únicamente a los casos que llamaban la atención del gobierno estadounidense por su vinculación a la Fundación Ford. Por el contrario, implicaron múltiples detenciones, la persecución a toda actividad política y gremial, y el secuestro y posterior desaparición de seis de sus integrantes. ${ }^{16}$ En cuanto al impacto de estas acciones en las agendas del INTA, una ex investigadora del organismo lo sintetiza de este modo:

\footnotetext{
Los equipos más diezmados, atacados e incluso los conocimientos negados como tales fueron aquellos que desde las diferentes disciplinas, trataron de integrar los aspectos sociales con los productivos, y de reconocer las profundas diferencias e inequidad entre los sectores rurales. El reconocimiento de los pequeños productores, y de sus requerimientos y demandas de tecnologías apropiadas, eran en sí mismo un pensamiento subversivo. $\frac{17}{}$
}

Los "conocimientos negados" involucraron la clausura de la EPG y el desmantelamiento de buena parte de sus equipos, y fuertes transformaciones en las dos líneas directrices del organismo: la investigación y la extensión rural. En cuanto a la primera, en una de las principales agendas, las investigaciones en fitomejoramiento, se impulsó la cesión de recursos filogenéticos al ámbito privado, que concentró la fase altamente rentable de la terminación de variedades, 
mientras que el INTA quedó relegado a la entrega de materiales genéticos, actividad de escasa rentabilidad. $\frac{18}{}$ Esta área de investigación no era menor. Para la década de 1970 la agricultura argentina experimentaba un proceso de transformaciones, vinculado como hito local a los ecos que la revolución verde generaba a nivel internacional. El núcleo de este cambio tecnológico, que a lo largo de esta década tornó vertiginoso el crecimiento de la producción agrícola pampeana hasta alcanzar una cosecha récord a nivel nacional en 1984-1985, fue protagonizado por el mejoramiento genético incorporado a las semillas. $\frac{19}{}$ El reverso de esta expansión estuvo protagonizado por las crisis de las economías regionales y el agravamiento de las condiciones de producción de los productores familiares y minifundistas. Por otro lado, durante la intervención militar (1976-1983) también se apuntó a la destrucción de lo que podríamos denominar "casos testigos" dentro del INTA. Entre ellos, se destruyó una línea de experimentación en genética aviar en la estación experimental de Pergamino (provincia de Buenos Aires), destinada a mejorar la calidad de alimentación de la población rural de zonas geográficas y socioeconómicas periféricas. La innovación se proponía seleccionar gallinas capaces de un régimen de alimentación que prescindiera del uso de alimentos balanceados e insumos farmacológicos. El investigador que lideraba el proyecto fue exonerado y fueron faenados los más de 20 mil animales seleccionados hasta la fecha. $\underline{20}$

Para la extensión rural se promovió la entrada masiva de becarios en el área con un "perfil apropiado para la transferencia de tecnología", que privilegió el contacto con técnicos del sector privado y productores capitalizados.1ㅡㄹ Esta reorientación fue simultánea al decrecimiento de las tareas dirigidas a mujeres rurales, y al desmantelamiento de uno de los principales canales institucionales, constitutivo además de la cultura extensionista del INTA, los Clubes 4-A enfocados en la juventud rural. Organizados a partir de actividades recreativas y de la enseñanza de técnicas agronómicas, mientras que en 1967 existían 445 clubes, con la participación de 11.628 jóvenes de ambos sexos y 90 asesores del INTA (INTA, 1967: 10), a fines de los años setenta, los Clubes 4-A tendían a desaparecer.르

Al igual que en otros sectores extractivos -pesquero, energético y minero-, la última dictadura marcó el momento en que la expansión agropecuaria se articuló a la especulación financiera, en el contexto de transformaciones que a partir de 1976 se produjeron en el patrón de acumulación local. $\underline{23}$ En este sentido, mientras que la introducción de mecanismos represivos incidió expulsado debates y sujetos críticos de las agendas de investigación y extensión, también las transformaciones de los patrones de acumulación, en especial en el agro, tuvieron su correlato en los contenidos y destinatarios de los planes de trabajo del organismo. Este proceso operó en forma bidireccional. Así como contenidos y orientaciones se vieron transformados por los cambios estructurales, muchas de las investigaciones producidas en el período también fueron insumos para la transformación del modelo productivo imperante en el agro. Como resultado, se intensificó un proceso de fragmentación y mercantilización del conocimiento producido por el INTA y el relegamiento de los pequeños productores y la familia rural como objetos de la extensión rural. $\underline{\underline{24}}$

Las transformaciones operadas durante la última dictadura iban a continuar en las décadas siguientes, en coincidencia con la orientación a largo plazo en la trayectoria institucional del INTA. Un hito lo constituiría, años más tarde, la propuesta de privatizar el organismo, en plena crisis neoliberal de la década de 1990. Si bien no llegó a materializarse, tanto el personal como los recursos fueron recortados drásticamente. Finalmente, si bien el presupuesto del organismo creció nominalmente entre 1976 y 1983, no fue suficiente para compensar la inflación. Esta situación, sumada a la interrupción de su autarquía financiera, derogada por el decreto-ley 22.294, motivó que, como estrategia de supervivencia, se incrementaran los convenios con una fracción crecientemente concentrada del sector privado. Este rasgo también dejaría su marca en la trayectoria institucional y sería profundizada cíclicamente en las crisis económicas venideras.

\section{La energía nuclear entre la "patria contratista" y la autonomía tecnológica}

La CNEA fue creada en 1950 bajo la dependencia de la Armada, en un contexto de fuerte impulso a la industrilización por sustitución de importaciones. ${ }^{25}$ Concebida como la institución que debía centralizar la política de un sector 
estratégico, ya desde sus primeros años definió los principales ejes que iban a orientar la política nuclear a lo largo de varias décadas: (i) metas de mediano y largo plazo orientados por la búsqueda de generación de capacidades autónomas (no por la tecnología de frontera); (ii) formación intensiva y acumulación de capacidades de I+D; (iii) creciente enraizamiento social y económico en áreas como medicina, agricultura, industria y, durante los años sesenta, energía; (iv) apoyo a la industria nacional y la conformación de una industria nuclear nacional; y (v) búsqueda de liderazgo regional.

En 1955 se crea el Instituto de Física de Bariloche (más tarde Instituto Balseiro), en 1958 se inaugura en CNEA el RA-1, el primer reactor de investigación construido en América Latina, y tres años más tarde el grupo de metalurgia crea el Servicio de Asistencia Técnica a la Industria (SATI), un organismo mixto que se propuso resolver problemas planteados por las propias industrias locales relacionadas con la metalurgia. El objetivo era difundir nuevos métodos de producción, el uso de nuevos metales, materias primas, máquinas e instrumentos, desarrollar mejores métodos de control de calidad, adecuarse al mercado local y, en palabras de Jorge Sabato, uno de los ideólogos del plan nuclear y creador del SATI, "preparar a la industria del país para la profunda transformación tecnológica que se producirá en los próximos años". $\underline{26}$

Durante los años sesenta se consolida la orientación de CNEA hacia las actividades de I+D vinculadas al desarrollo de reactores de investigación y al ciclo de combustible nuclear y se comienza a gestionar la compra de la primera central de potencia. Cuando se produjo el golpe de Estado, a fines de junio de 1966, era evidente el avance del capital extranjero industrial, su capacidad de ejercer "un alto poder oligopólico en los mercados industriales más dinámicos" y el consecuente desplazamiento de empresas de capital nacional, con especial impacto entre las empresas pequeñas y medianas. $\underline{27}$

Al año siguiente, se inauguró el reactor RA-3. En su construcción habían participado más de 60 empresas nacionales. Poco más tarde, un grupo de la CNEA logró reprocesar plutonio a escala de laboratorio y también se comenzó a desarrollar la tecnología de producción de agua pesada. En diciembre de 1970, la ley de "Compre nacional" surge como producto del aprendizaje producido por el proceso de compra de la primera central de potencia a la empresa alemana Siemens. ${ }^{28}$ Poco antes de las elecciones de marzo de 1971, el presidente de facto y general Alejandro Lanusse anunció que la segunda central de potencia sería construida en Río Tercero, provincia de Córdoba, por el consorcio integrado por la empresa estatal canadiense AECL y la italiana Italimpiant.

CNEA impulsó la creación de dos consorcios donde intervenían empresas argentinas de ingeniería y montaje. En el caso de NUCLAR, integrado por las cinco empresas constructoras más importantes, el objetivo era "armar un contratista lo suficientemente fuerte como para competir en el exterior". A pesar del "pésimo nivel" de los dirigentes de las empresas que componían NUCLAR y de que "no comparten un objetivo común sino que hay intereses encontrados entre los socios, prácticamente desde el inicio", el consorcio llegó a cotizar el montaje de una central de la empresa norteamericana Westinghouse en Egipto. $\underline{\underline{29}}$

Para 1973, cuando el peronismo gana las elecciones nacionales, el desarrollo nuclear argentino era el segundo más avanzado, detrás de la India, del mundo en desarrollo. $\underline{30}$ CNEA ya gestionaba un plan de construcción de centrales de potencia que se proponía una participación creciente de la industria nacional. La central Atucha I, luego de varios retrasos en el calendario, entró en operación el 20 de marzo de 1974. SATI había conseguido colocar una lista de órdenes de compra y obra civil que permitía concluir que la participación de la industria nacional había sido de alrededor del 40\%.․․

\section{CNEA en dictadura}

A partir del golpe cívico-militar que expulsó de la presidencia a María Estela Martínez de Perón a fines de marzo de 1976, el desarrollo nuclear comenzó a acelerarse. Al mismo tiempo, Si bien al comienzo de la última dictadura gran parte del personal de la CNEA manifestó su oposición al régimen militar, la escalada de la represión fue silenciando las 
manifestaciones de crítica u oposición explícitas. Poco más de diez científicos de la CNEA fueron arrestados en abril de 1976. El descubrimiento de alrededor de 200 legajos personales "paralelos", con información ideológica, gremial y política, evidencian que el personal de la CNEA estuvo bajo vigilancia. De acuerdo con Arcomano, a través de la Ley de Prescindibilidad se echó a 107 trabajadores -sin indemnización, quedaron cesantes 120, y 370 renunciaron por el clima de persecución imperante. ${ }^{32}$ Como contrapartida, fue incorporado numeroso personal contratado, previamente supervisado por la Secretaría de Inteligencia del Estado. A fines de 1976 habían sido desvinculados por distintos mecanismos alrededor de 600 profesionales, técnicos y administrativos de la institución. El complemento necesario de una política económica que inauguraba un proceso acelerado de desindustrialización y precarización laboral fue la construcción de una estructura represiva que se propuso la aplicación a escala nacional de prácticas sistematizadas de terrorismo de Estado, que alcanzaron la dimensión de genocidio. En CNEA quince trabajadores figuran hoy en la lista de desaparecidos. ${ }^{33}$

La nueva dictadura nombró como presidente de CNEA al capitán (más tarde vicealmirante) Carlos Castro Madero, que había egresado de la Escuela Naval, y se había doctorado en física en el Instituto Balseiro. Castro Madero sostuvo públicamente que la inversión estimada en el área nuclear para los próximos diez años iba a ser "del orden de 5500 millones de dólares, de los cuales 3500 millones serán insumos nacionales que deberán ser provistos por el Tesoro Nacional". También afirmaba que la Argentina ya estaba capacitada para "asumir la responsabilidad de la dirección, construcción, montaje y puesta en operación de las próximas centrales". . $^{3}$ El objetivo era liberar cuanto antes al país de los contratos conocidos como "llave en mano".

Las metas de CNEA eran alcanzar el dominio de las tecnologías del ciclo completo del combustible nuclear, y dar señales claras de la orientación pacífica del programa nuclear argentino. Ahora bien, el hecho de estar al frente del proyecto nuclear de una dictadura iba a debilitar las argumentaciones de Castro Madero, que a lo largo de toda su gestión, igual que en sus escritos posteriores, evitó cualquier alusión a las prácticas de terrorismo de Estado. Trabajaban alrededor de 4000 personas en CNEA, de las cuales 1900 eran profesionales y técnicos. ${ }^{35}$ Las inversiones anunciadas para el sector nuclear y la orientación "industrialista" de CNEA parecían ir a contramano de una política económica de corte refundacional, que iniciaba un ciclo de desindustrialización, con costos sociales enormes, "en favor de los dueños del dinero".$\underline{36}$

La concepción antiestatista y antiproteccionista se articulaba con la necesidad de ir eliminando del mercado a la "pléyade de pequeñas y medianas empresas". $\underline{37}$ Frente a este escenario, el desarrollo nuclear era uno de los focos de tensión dentro de la propia cúpula militar. Como sostiene Sidicaro, desde los comienzos del gobierno militar coexistieron dos proyectos divergentes. Junto al programa de apertura indiscriminada impulsado por el equipo económico de Martínez de Hoz, aparece una concepción desarrollista, que continúa asignando un papel estratégico al Estado en la determinación de los objetivos económicos y sociales. $\stackrel{38}{ }$ Concepción que se construye como estrategia de reproducción de una fracción de las propias fuerzas armadas, dada su pertenencia al complejo militar-industrial estatal. La cúpula militar gobernante y sus cuadros civiles logran un equilibrio político inestable por el cual los desarrollistas no plantean una oposición irreductible a las reformas económicas del grupo de Martínez de Hoz y, a cambio, los liberales aprueban los gastos militares, el sostenimiento de las empresas del Estado y el plan de obras públicas, que iban a quedar en manos de los empresarios socios de la dictadura. En este escenario, el desarrollo nuclear no fue una excepción dentro de la nueva configuración de relaciones corporativas entre segmentos del Estado autoritario y un sector privilegiado de grandes empresas oligopólicas vinculadas a los capitales transnacionales.

Como sostiene Pucciarelli, este conglomerado empresarial fue beneficiado por la proliferación de contratos por la provisión de obras, de bienes, materiales estratégicos y asistencia tecnológica "a las nuevas ramas en expansión monopolizadas por el Estado, tales como la industria bélica, aeronáutica, y nuclear", además de otros beneficios vinculados a la ley de promoción industrial y el nuevo panorama de negocios relacionado con la valorización financiera. ${ }^{39} \mathrm{Si}$ los inicios de este proceso pueden ubicarse en la gestión de Krieger Vasena, la mutación del contexto macroeconómico transformó al desarrollo nuclear - un sector capital intensivo - en instrumento para la consolidación de la llamada "patria contratista". Una consecuencia crucial de estas transformaciones será el sobredimensionamiento del plan nuclear. 
Desde el plano internacional, los planes iniciales de Castro Madero se vieron obstaculizados por las iniciativas acordadas por los países exportadores de tecnología nuclear contra el desarrollo de planes nucleares de países en desarrollo. Por iniciativa de los Estados Unidos, se iniciaron en 1974 reuniones secretas de los países exportadores de tecnología nuclear, más tarde conocido como el "Club de Londres". 40 El objetivo explicitado era poner restricciones al comercio de equipos y tecnologías nucleares y evitar que la competencia entre los países exportadores debilitara las salvaguardias. Finalmente, ignorando al Organismo Internacional de Energía Atómica (OIEA), fueron redactadas en secreto y aprobadas en septiembre de 1977 las llamadas "Pautas de Londres", aunque finalmente fueron comunicadas al OIEA en notas de enero de 1978. Este proceso acompañó el endurecimiento de la posición de los Estados Unidos. La administración Carter prohibió a proveedores norteamericanos de tecnología nuclear toda venta a países que, como Argentina, no hubieran firmado el Tratado de No Proliferación Nuclear (TNP).

A partir de este momento, la administración Carter iba a mantener como temas centrales de su agenda con la Argentina la cuestión de los derechos humanos y la ratificación de los tratados de no proliferación. Canadá se sumó a la política de presiones de los Estados Unidos, desconociendo los compromisos adquiridos con la Argentina, entre ellos el acuerdo de transferencia de tecnología como parte de la compra de la segunda central de potencia.11 Esto ocurría mientras funcionarios de CNEA, a comienzos de noviembre de 1977, se encontraban firmando un acuerdo con Perú para la construcción de un Centro de Investigación Nuclear en Guarangal, a 35 kilómetros de Lima, que incluía el diseño y construcción de un reactor de investigación de 10 MW. Para Castro Madero, el convenio con Perú era algo inédito en América latina y un ejemplo privilegiado de lo que se entiende por "transferencia horizontal". Estados Unidos reaccionó al acuerdo negando el uranio enriquecido para que la Argentina pudiera fabricar los elementos combustibles del reactor peruano. Como respuesta, Castro Madero explicaba públicamente que resultaba muy difícil "discriminar hasta dónde se trata de evitar la proliferación y hasta dónde se permite que existan monopolios, que existan intereses comerciales o que exista el interés de que algunos países no tengan la posibilidad de desarrollar sus planes autónomos". 42

Para consternación de la administración Carter, Castro Madero anunció que la Argentina había contratado el año anterior a la empresa Techint para comenzar a construir en el Centro Atómico de Ezeiza una planta experimental para reprocesar plutonio, que podría estar terminada a comienzos de los ochenta. Desafiando los esfuerzos de los Estados Unidos para detener este proyecto, Castro Madero afirmaba: "Ahora los Estados Unidos dicen 'no reprocesen'. Al día siguiente, ellos dirán sí [...] Para un país como el nuestro, toma tiempo desarrollar una nueva tecnología. Por eso estamos planificando llegar preparados a la década de 1990 para estar en posición de decidir por nosotros mismos si reprocesar o no". $\underline{43}$

Mientras se anunciaba la construcción de una nueva planta que fabricaría los elementos combustibles necesarios para operar Atucha I a partir del uranio natural argentino, en enero de 1979 el gobierno de facto promulgó un decreto que aprobaba un ambicioso plan nuclear que autorizaba la construcción de cuatro reactores de 600 MW en los próximos veinte años y una planta de producción de agua pesada a escala industrial. En noviembre, la compañía alemana KWU ganó el contrato por 1300 millones de dólares para construir Atucha II, mientras que la firma suiza Sulzer Brothers obtuvo el contrato por 300 millones de dólares para construir una planta comercial de agua pesada con una capacidad de producción de 250 toneladas anuales en Arroyito, provincia de Neuquén. En ese momento se hizo el llamado a licitación para la tercera central nuclear. Como consecuencia de estos planes, en 1980 el presupuesto de CNEA superó los 1000 millones de dólares anuales. $\underline{44}$

En un contexto de crisis económica, los ambiciosos planes de CNEA comenzaron a ser amenazados por la escasez de fondos. El estancamiento económico - a esta altura la deuda externa era de 39.000 millones de dólares - comenzó a tornarse una barrera infranqueable. Como compensación parcial, a mediados de 1982 se produjo un giro en la política norteamericana, cuando el secretario de Energía de la administración Reagan autorizó una exportación de tecnología para la planta de agua pesada.

El gobierno militar, debilitado por la derrota en la guerra de Malvinas, debió entonces comenzar a negociar el retorno a la democracia. En su último tramo, en mayo de 1983, se inauguró la central de Embalse, con una participación 
del $51 \%$ de empresas nacionales. A fines de octubre, Raúl Alfonsín ganó las elecciones presidenciales y debía asumir la presidencia el 10 de diciembre. En un contexto de inflación anual del 400\%, el presidente electo recibió la noticia de la existencia de una planta de enriquecimiento de uranio en la Patagonia, que había sido desarrollada en secreto por la empresa pública INVAP -creada a fines de 1976 como desprendimiento de CNEA- con un costo total de 62,5 millones de dólares. ${ }^{45}$ Alfonsín pidió que se hiciera pública la existencia de esta instalación antes de su asunción. El anuncio público de Castro Madero, el 18 de noviembre de 1983, tomó de sorpresa a las agencias de inteligencia norteamericanas. En ese momento, la Argentina era considerado el tercer mayor proveedor del mundo de asistencia nuclear a otros países en desarrollo y EEUU consideraba a la Argentina un país proliferador. Una vez caída la dictadura, la herencia de este gigante con pies de barro -en la forma de deuda externa y de onerosas obras en curso en manos de las grandes empresas contratistas- iba a ser una carga pesada para la incipiente democracia.

La transformación traumática del contexto socio-económico hacia la valorización financiera y la promoción de la patria contratista resignificó el sentido y la escala de la política nuclear. La consecuencia más visible de esta resignificación fue un desdoblamiento. Por un lado, las grandes obras nucleares impulsadas durante la última dictadura desplazaron el foco desde los objetivos industrialistas -que incluían a las pequeñas y medianas empresas-, hacia el grupo de capitales concentrados privilegiados por su cercanía y funcionalidad al poder de facto y a su capacidad de lobby en el ámbito de los capitales trasnacionales. Por otro lado, algunos de los objetivos ideológicos, ambiguamente encapsulados en la noción de autonomía tecnológica mantuvieron su vigencia.

\section{CONICET: de la articulación universitaria a los "Institutos propios"}

Poco tiempo después de la creación de la CNEA, en mayo de 1950, y aludiendo específicamente a su instrumentación, el presidente Perón estableció en julio del mismo año, mediante el decreto № 13.443, la creación de la Dirección Nacional de Investigaciones Técnicas, dependiente del Ministerio de Asuntos Técnicos. En mayo del año siguiente, la organización del Consejo Nacional De Investigaciones Técnicas y Científicas (CONITYC) daría un paso más en la competencia estatal sobre las actividades científicas y tecnológicas. El objetivo era lograr una articulación que brindara herramientas del campo tecnológico y científico a las metas del primer plan quinquenal, señalando la importancia de generar una coordinación nacional de las actividades de investigación en miras de alcanzar las transformaciones en la estructura productiva. Con la interrupción democrática a manos de la autodenominada "Revolución Libertadora" en 1955, y como consecuencia de la fuerte política represiva de "desperonización" de la sociedad argentina, el CONITyC fue suprimido, al igual que otras dependencias estatales.

De estructura e iniciativas similares, pero bajo la impronta política de la Libertadora, en febrero de 1958 fue creado el Consejo Nacional de Investigaciones Científicas y Técnicas (CONICET). En este sentido, según Casalet, la creación del Consejo "respondió más a una reivindicación sectorial de los científicos, a la necesidad de prestigio del Estado por su apoyo al desarrollo científico y a la voluntad modernizadora -clima de época- de los protagonistas del momento, que a una efectiva demanda por parte de los sectores de la producción". ${ }^{46}$ El decreto 1291/58 estableció su funcionamiento como ente autárquico del Estado y explicitó su tarea de "promover, coordinar y orientar las investigaciones en el campo de las ciencias puras y de las aplicadas".

Con sede en la ciudad de Buenos Aires, su primer directorio estuvo presidido por el nobel en Fisiología, el doctor Bernardo Alberto Houssay. Las ciencias biomédicas ocuparon un lugar destacado, a diferencia del reducido peso que inicialmente tuvieron las ciencias sociales y las investigaciones tecnológicas. En el primer directorio fueron designados siete directores provenientes de disciplinas biomédicas, cinco de ciencias exactas y naturales, uno por las áreas tecnológicas y ninguno por las ciencias sociales.

Desde su fundación, el CONICET tuvo como principal objetivo la promoción de la investigación. Para la formación de investigadores dedicó buena parte de sus recursos al establecimiento de un programa de becas orientadas a gra- 
duados universitarios con vocación científica, junto a un programa de subsidios orientados a financiar equipamientos e investigaciones. Estuvo desde sus inicios facultado para crear y subvencionar institutos, laboratorios y otros centros de investigación, que podrían funcionar en universidades y otras instituciones oficiales. Además, en su artículo segundo establecía que debería "Auspiciar por los medios apropiados el desarrollo de las investigaciones en la industria privada y brindar a ésta su asesoramiento en materia científico-técnica". ${ }^{47}$ Asumiendo la responsabilidad de coordinar las tareas de investigación realizadas en el país, instituyó el otorgamiento de subsidios y creó un sistema de becas de especialización y formación. Un paso fundamental lo constituyó la organización de la Carrera de Investigador Científico (CIC), de dedicación exclusiva, creada en 1961 e inspirada en la experiencia francesa. Muchos de los miembros de la Carrera tenían como lugar de trabajo universidades nacionales, lo que inicialmente contribuyó a articular las actividades de docencia e investigación, mejorando el nivel de la enseñanza al tiempo que se promovía la formación de investigadores jóvenes. ${ }^{48}$ El método por excelencia fue la evaluación entre pares, a partir de la conformación de comisiones disciplinares y rigurosos concursos obligatorios para acceder tanto a los programas de becas, como al ingreso a la Carrera.

\section{La dictadura en el CONICET: institutos, espionaje y fuga}

En 1976, la llegada de la dictadura no pasó inadvertida en el CONICET. El mecanismo de evaluación por pares se vio fuertemente limitado, y en muchos casos interrumpido, por las presiones políticas e ideológicas. En un país sometido al derrotero de sucesivas dictaduras, no era la primera vez que esto ocurría en la historia del Consejo. Durante el régimen encabezado por el general Onganía (1966- 1970), en especial luego de la llamada Noche de los Bastones Largos (1966), y luego durante el gobierno constitucional de María Estela Martínez de Perón (1974-1976), se habían registrado numerosos episodios en este sentido. A partir de 1976, una vez producido el último golpe de Estado, la persecución ideológica y las limitaciones para el libre desarrollo de las actividades se reflejaron en un fuerte éxodo de científicos, y en distintos episodios de represión que culminaron con la desaparición, algunos en sus propios lugares de trabajo, y la cesantía de cientos de trabajadores de la ciencia y la tecnología en los distintos organismos de CyT estatales a los que se vinculaban los integrantes del CONICET, ya fuera como becarios o investigadores.

El éxodo o Brain Drain, no solamente conllevó la pérdida de investigadores altamente calificados en sus diferentes áreas. El contenido político de esta fuga también implicó erradicar las visiones que ponían en tensión la importación de categorías extranjeras, la ausencia de soberanía en la configuración en las agendas de investigación y la necesidad de articular el quehacer científico y tecnológico a la transformación social. Estos enfoques, impulsados durante la década de 1960 y durante la primera mitad de la de 1970 por autores como Amílcar Herrera y Oscar Varsavsky, posteriormente conceptualizados junto a otros pensadores como referentes del Pensamiento Latinoamericano en Ciencia y Tecnología (PLACTED), también vieron coartados su capacidad de expansión en la esfera local.

En cuanto a la configuración institucional, dentro de la estructura institucional del CONICET existía una figura, que inicialmente tuvo un escaso peso: los "institutos propios", es decir, directamente dependientes del Consejo. Al morir el primer director del organismo, Houssay, en 1971, existían solamente tres. En cambio, en 1983, se contabilizaban ciento dieciséis institutos propios. ${ }^{49}$ En medio, había transcurrido la dictadura. ¿Qué implicó este crecimiento? Fundamentalmente, fue un golpe al sistema universitario. Si bien la política de creación de institutos se intensificó en el decenio 1966-1976, a partir de 1976 se volvió hegemónica. El desplazamiento de la investigación a ámbitos extra-universitarios mediante la proliferación de numerosos ámbitos propios, de difícil y dudoso control, contribuyó al aislamiento de las universidades, identificadas por el régimen a la "subversión" por la agitada experiencia política de la militancia estudiantil, y la capacidad de generarse como usinas críticas. Así, mientras que la Universidad era privada de los recursos financieros necesarios para su crecimiento, el CONICET se orientó a la creación de institutos y programas de investigación desconectados de la función universitaria, y centrados en áreas muy específicas..$\underline{50}$ 
La proliferación de institutos fue realizada en simultaneidad a la promoción de los Centros Regionales, para lo que fue obtenido un cuantioso préstamo del BID de 42 millones de USD en 1979. En este sentido, Feld remarca que los criterios de evaluación y las principales líneas de investigación promovidas tuvieron continuidad con las señaladas como prioritarias en la segunda mitad de la década de 1960.51 Así, las rupturas en las políticas científicas y en la configuración del CONICET producidas como efecto de la última dictadura también tuvieron fuertes elementos de continuidad con concepciones y herramientas diseñadas en la década previa. En este plano también se inscribía el propio accionar de los institutos propios, ya que luego de 1966 la misión de promoción de la investigación otorgada al Consejo había mutado a la de ejecución.

Por otro lado, esta forma de institucionalidad extra-universitaria, los institutos, también estuvo asociada a la creación de numerosas Fundaciones, creadas por algunos investigadores para recibir subsidios de CONICET, con el objetivo de financiar las investigaciones que se desarrollaban en los institutos. Según un informe institucional realizado en 1989 para evaluar el impacto de la dictadura, titulado "Informe sobre investigaciones de hechos ocurridos en el CONICET. Período 1976-1983", estas fundaciones habían malversado los fondos. El informe revisaba una causa judicial abierta por ese delito e indicaba:

(...) queda claro, según los fiscales, que con la excusa de administración de fondos para el CONICET, estas fundaciones subsistieron exclusivamente con fondos públicos, se enriquecieron patrimonialmente y llegaron a funcionar como verdaderas empresas privadas, logrando así el desvío y el apoderamiento de los fondos previstos y otorgados para la investigación. $\frac{52}{2}$

Con el retorno de la democracia en 1983, la carta orgánica del Consejo fue modificada. Se estableció un directorio integrado por seis miembros con dedicación de tiempo completo, y un consejo asesor de dieciocho miembros honorarios. Una de las principales preocupaciones de esta etapa se concentró en el éxodo de cientos de científicos radicados en el exterior. Si bien en el futuro inmediato no habrían de producirse nuevas interrupciones democráticas, en las décadas venideras la "fuga de cerebros" continuaría ligado a la sucesión de las crisis económicas y políticas. Por su parte, pese a las iniciativas diseñadas para contrarrestar el efecto, el CONICET tardaría años en recomponer su articulación al ámbito universitario, desafío que no lograría del todo.

\section{Conclusiones}

El estudio de las principales trayectorias institucionales argentinas de CyT durante sus respectivas intervenciones militares (1976-1983) permitió identificar patrones comunes en la implementación de mecanismos represivos, impactos asimétricos en las asignaciones y orientaciones de sus presupuestos, y transformaciones en sus agendas de trabajo. Al mismo tiempo, la exploración en profundidad de dos comunidades científico-tecnológicas (INTA y CNEA), y la reconstrucción de la trayectoria del organismo llamado a coordinar el complejo de CyT (el CONICET), permite aseverar que estos aspectos, plausibles de ser abordados en sus especificidades desde el plano analítico, operaron en forma conjunta. Fue precisamente esta articulación entre dinámicas represivas y disciplinamiento social, transformaciones económicas y reconfiguraciones institucionales, la que moldeó el mapa del área de ciencia y técnica en la Argentina de la última dictadura.

Como indicó Adler en un capítulo pionero dedicado al estudio de la política de CyT argentina entre 1966 y 1982, en la distribución de los recursos agrupados en la «Finalidad 8» del presupuesto nacional, el correspondiente al área de CyT indica que tanto la CNEA como el CONICET incrementaron su participación, mientras que la de las universidades disminuyó drásticamente a partir de 1975. $\underline{53}$ Como fue señalado, el crecimiento presupuestario de CONICET estuvo asociado a la proliferación de institutos propios desvinculados de las universidades, mientras que el desorbitante crecimiento de la CNEA fue simultáneo a la intensificación de lazos con la «patria contratista», mediante la participación de grandes 
firmas — como Techint—que funcionaron asociadas a los emprendimientos del sector nuclear. En cuanto al INTA, si bien su presupuesto creció nominalmente, éste no logró paliar la inflación, y este organismo perdió su autarquía financiera.

Mientras que los organismos experimentaron diferencias en sus asignaciones presupuestarias, inscribieron sus producciones tecnocientíficas en una dinámica de creciente apropiación privada de los conocimientos y resultados de investigación obtenidos con fondos públicos. Esta dinámica incluyó discontinuidad de líneas de trabajo (en el caso del INTA), desvinculaciones explícitas de ámbitos institucionales considerados "peligrosos" como las universidades (en el caso del CONICET), y transformaciones en las escalas de los principales proyectos tecnológicos (en el caso de la CNEA). Estos movimientos expresaron rupturas en relación a los destinatarios de los conocimientos producidos. El INTA registró relevantes transformaciones que alcanzaron tanto a sus agendas de investigación y extensión rural, como a sus integrantes. Para el ámbito rural esto significó dejar fuera de las agendas a los productores de menores recursos, dando continuidad a orientaciones previas que ponían énfasis en la articulación con la agricultura comercial de gran escala. En el CONICET fue propiciado un crecimiento de estructuras autónomas (los "institutos propios") como estrategia de desvinculación y desfinanciamiento de las universidades nacionales. Finalmente, para el área nuclear, en la CNEA se privilegiaron los consorcios con grandes grupos transnacionales, en desmedro de proyectos orientados a la industria local.

Las rupturas provocadas sobre las trayectorias institucionales y las políticas sectoriales respondieron a la redefinición explícita de los roles institucionales -tanto en términos de funciones y metas, como de representaciones y de ideologías- y de sus agendas de investigación y desarrollo. En este sentido, en los términos propuestos por Saraiva y Wise, es posible indicar la existencia de una "co-evolución" entre las principales transformaciones económicas, las políticas sectoriales y la orientación de la producción científica y tecnológica. $\underline{54}$ Así, en el caso del INTA, los cambios en contenidos y destinatarios de las agendas dialogaron con las transformaciones productivas de un agro en plena expansión de su frontera agrícola, polarizado socialmente bajo la primacía del sector pampeano de exportación, y con políticas agropecuarias que liberalizaron el comercio exterior otorgando reducciones arancelarias a insumos clave y desmantelando las instancias regulatorias. Por su parte, el sector nuclear reveló un fuerte crecimiento, materializado en las asignaciones presupuestarias, que fue tan intenso como drástico el cambio de escala de los proyectos, la intervención de consorcios público-privados que favorecieron la trama corporativa del Estado, y las presiones internacionales que obstruyeron el despegue local. Finalmente, la trayectoria del CONICET expuso la estrategia de debilitamiento del complejo universitario, enfocada como política educativa implícita.

En pocos años, estas transformaciones impactaron en las modalidades de enraizamiento económico y social de las instituciones y generaron consecuencias perdurables en el tiempo, tanto en la organización de las prácticas científicas y tecnológicas y los contenidos de las agendas, como en los colectivos sociales que eran sus destinatarios. Para 1983, mientras que la dictadura había terminado, también en el área de ciencia y técnica su herencia comenzaba a gestarse como el mayor desafío para el nuevo ciclo democrático.

\section{Notas y referencias bibliográficas}

Diego Hurtado es pesquisador del Consejo Nacional de Investigaciones Científicas y Técnicas (CONICET) y miembro del Centro de Estudios de Historia de la Ciencia y la Técnica "José Babini", Universidad Nacional de San Martín (UNSAM), Argentina. E-mail: dhurtado2003@yahoo.com.ar.

Cecilia Gárgano es pesquisadora del Consejo Nacional de Investigaciones Científicas y Técnicas (CONICET) y miembro del Centro de Estudios de Historia de la Ciencia y la Técnica "José Babini", Universidad Nacional de San Martín (UNSAM), Argentina. E-mail: garganocecilia@gmail.com.

1 Entre otros, véase: ADLER, Emmanuel. The power of ideology. The quest for technological autonomy in Argentina and Brazil. Berkeley: University of California Press, 1987. BEKERMAN, Fabiana. The Scientific Field During Argentina's Latest Military Dictatorship (1976-1983): Contraction of Public Universities and Expansion of the National Council for Scientific and Technological Research (CONICET). Minerva. 1, 17, 2013. DOI 10.1007/sl 1024-013-9227-9. GÁRGANO, Cecilia. Experimentación científica, genética aviar y dictadura militar en el Instituto Nacional de Tecnología Agropecuaria (1956-1976). Mundo Agrario. 28, 15, 2014. Disponible en: http://www.mundoagrario.unlp.edu.ar/article/view/MAv15n01. HURTADO, Diego. Periferia y fronteras tecnológicas. Energía nuclear y dictadura militar en la Argentina (1976-1983). Revista Iberoamericana de Ciencia, Tecnología y Sociedad, 13, p. 27-64, 2009. 

sociedad política en la Argentina. Buenos Aires: Hyspamérica, 1981.

3 Temáticas que han sido desarrolladas en AZPIAZU, Daniel, BASUALDO, Eduardo y NOCHTEFF, Hugo. La revolución tecnológica y las políticas hegemónicas. Buenos. Aires: Lagasa. 1998. PUCCIARELLI, Alfredo. La patria contratista. El nuevo discurso liberal de la dictadura encubre una vieja práctica corporativa. En PUCCIARELLI, Alfredo. Empresarios, tecnócratas y militares. Buenos Aires: Siglo Veintiuno, 2004. p. 99-171.

4 Decreto-Ley 21.680 del 4 de diciembre de 1956, firmado por el presidente de facto Aramburu y por su gabinete. Sobre los orígenes del INTA y su trayectoria hasta el comienzo de la última dictadura, véase CARBALLO, Carlos. Cincuenta años de agricultura familiar y desarrollo rural en el INTA. Revista Interdisciplinaria de Estudios Agrarios. 26, 27, p. 63-93, 2007. LOSADA, Flora. La institucionalización de la extensión rural con la creación del INTA (1957). Documentos del CIEA. 1, 27-35, 2003. VALEIRAS, Juan. Principales instituciones especializadas en investigación y extensión. En: OTEIZA, Enrique (Comp.) La política de investigación científica y tecnológica argentina. Historia y perspectivas. Buenos Aires: Centro Editor de América Latina, 1992. p. 168-182.

SAUCEDE, María Cristina. El caso de Agronomía. En MINCyT (Org.) Ruptura y reconstrucción de la Ciencia Argentina. Buenos Aires: Ministerio de Ciencia, Tecnología e Innovación productiva, 2007. pp. 103-105.

6 Entre otros, cabe mencionar las creaciones del Instituto Nacional de Investigación Agropecuaria (INIA) de Ecuador (1959), el INIA de México (1960), el Instituto Colombiano Agropecuario (1963), el INIA de Chile (1964).

7 En particular, nos referimos a la incidencia en los planes de desarrollo rural, a lo largo de las décadas de 1950 y 1960 , de un conjunto de organismos que posteriormente confluyeron en el Comité Interamericano de Desarrollo Agrícola (CIDA).

8 LEÓN, Carlos Alberto y LOSADA, Flora. Ciencia y tecnología agropecuarias antes de la creación del Instituto Nacional de Tecnología Agropecuaria. Revista Interdisciplinaria de Estudios Agrarios, 16, p. 35-90, 2002.

9 La EPG surgió como producto de un convenio entre el Instituto Interamericano de Ciencias Agrícolas (IICA) y la Universidades Nacionales de La Plata y de Buenos Aires, GÁRGANO, Cecilia. Ciencia, Tecnología y Dictadura: la reorganización de las agendas de investigación y extensión del Instituto Nacional de Tecnología Agropecuaria (INTA) durante la última dictadura cívico-militar argentina (1976-1983). Realidad Económica. 258, p. 120- $149,2011$.

10 Idem, p.129-132.

11 Muchos testimonios figuran en la causa judicial impulsada por Nicolás y Guido Prividera, a quienes agradecemos la provisión del material.

12 GÁRGANO, Cecilia. Tecnología agropecuaria y dictadura militar. En GÁRGANO, Cecilia (Comp.) Ciencia en Dictadura. Trayectorias, agendas de investigación y políticas represivas en Argentina. Buenos Aires: Ediciones INTA. p. 115-137, 2015.

13 Reca había sido secretario nacional de Agricultura, Ganadería y Pesca entre septiembre de 1975 y febrero de 1976.

14 RUDBECK, James. Ford Foundation Call Re Employees at Castelar, [Memorándum del agregado agrícola James Rudbeck a la embajada estadounidense]. Colección State Argentina Declassification Project (1975-1984). Recuperado de: http://foia.state.gov/SearchColls/CollsSearch.asp

15 WADE, Nicholas. Repression in Argentina: Scientists Caught Up in Tide of Terror. Science. 194, 4272, p. 1397-1399, 1987.

16 Tres asesinatos se produjeron con anterioridad al golpe militar: el del estudiante Néstor Mocoroa (1973), el extensionista Carlos Llerena Rosas asesinado por la agencia paraestatal Alianza Anticomunista Argentina (1974), y el del ingeniero agrónomo Juan Carlos Prádanos (1976). En dictadura, fueron secuestrados y desaparecidos Marta Sierra de Prividera (1976), Gustavo Giombini y Carlos Costa, éste último del propio Instituto de Suelos de INTA Castelar, (1976), Hilda Leikis (1976), María José Rapela, bibliotecaria, embarazada al momento de su desaparición (1977), Rita Alés de Espíndola, extensionista, cuya hija nació en cautiverio (1977) y Miguel “Chufo” Villarreal (1978), quien llegó sin vida a la ex Escuela de Mecánica de la Armada (ESMA), GÁRGANO, 2015, op. cit, p. 118.

17 SAUCEDE, op. cit., 2007. p. 104.

18 GÁRGANO, op. cit., 2015, p. 137.

19 BALSA, Javier. Los sujetos sociales de la expansión agrícola en las décadas de 1970 y 1980 . En BALSA, Javier. El desvanecimiento del mundo chacarero. Transformaciones sociales en la agricultura bonaerense. 1937-1988. pp. 133-161. Buenos Aires: Universidad Nacional de Ouilmes, 2006.

20 GÁRGANO, op. cit., 2014.

21 ALEMANY, Carlos. Apuntes para la construcción de los períodos históricos de la Extensión Rural del INTA. En CIMADEVILLA, Gustavo y THORNTON, Ricardo. La Extensión Rural en debate: concepciones, retrospectivas, cambios y estrategias para el Mercosur, pp.137-171. Buenos aires: Ediciones INTA. 2003. p. 8.

22 GÁRGANO, Cecilia. Rupturas y continuidades en el perfil de la extensión rural en Argentina. Ouinto Sol, 27, 2, 2017. D0l: http://dx.doi.org/10.19137/ qs.v21i2.999

23 BASUALDO, Eduardo y KHAVISSE, Miguel. El nuevo poder terrateniente. Investigación sobre los nuevos y viejos propietarios de tierras de la Provincia de Buenos Aires. Buenos Aires: Planeta, 1993.

24 GÁRGANO, op. cit., 2011, p.122.

25 Decreto 10.936 del 31 de mayo de 1950. Por decreto 9.697, del 17 de mayo de 1951 se crea la Dirección Nacional de la Energía Atómica (DNEA) y otros organismos, que años más tarde se fusionarían con la CNEA, el conjunto mantendría este nombre.

26 SABATO, Jorge. Plan de actividades del Departamento de Metalurgia de la Comisión Nacional de Energía Atómica, Argentina. Conferencia de Expertos Latinoamericanos en Metalurgia de Transformación, Buenos Aires, CNEA-OEA-INTI-US Air Force Office of Scientific Research, 18-23 de agosto, 1964. p. 4-8.

27 AZPIAZU ET AL, op. cit, 1988, p. 38-40.

28 La Ley 18.875/70 obligaba a las dependencias estatales a adquirir bienes y servicios a firmas argentinas.

29 QUNTANA, Guillermo. (coord.). Gastos en inversión en el sector nuclear: gestión y organización. En: QUINTANA, Guillermo. Análisis de instituciones científicas y tecnológicas. La Comisión Nacional de Energía Atómica. Buenos Aires: Universidad de Buenos Aires, 1995. p. 136.

30 REDICK, John. Regional Nuclear Arms Control in Latin America. International. 29, 2, p. 415-45, 1975.

31 QUILICI, Domingo. Desarrollo de proveedores para la industria nuclear argentina. Visión desde las Centrales Nucleares. H-industri@. Revista de historia de la industria argentina y latinoamericana. 2, 2, 2008, p. 1-23. p. 7.

32 ARCOMANO, R. Los desaparecidos de la CNEA. Miradas al Sur, 5, 219, 2012. Ver en: http://sur.infonews.com/notas/los-desaparecidos-de-la-cnea 

CNEA, la Asociación de Trabajadores del Estado. Buenos Aires, 22 de marzo, 2006.

34 CASTRO MADERO, Carlos. Argentina. Situación nuclear actual. Estrategia, 51, 30-41, 1978.

35 Comisión Nacional de Energía Atómica. Memoria Anual 1978. Buenos Aires: CNEA, 1978. p. 27.

36 SCHVARZER, Jorge. Implantación de un modelo económico. La experiencia argentina entre 1975 y el 2000. Buenos Aires: A-Z Editora, 1988. p.34.

37 PUCCIARELLI, Alfredo, 2004, op. cit., p. 113

38 SIDICARO, Roberto. El régimen autoritario de 1976: refundación frustrada y contrarrevolución exitosa. En: QUIROGA, Horacio y TCACHT, Carlos (comps.). A veinte años del golpe. Con memoria democrática. Rosario: Homo Sapiens, p. 9-25, 1996.p. 17.

39 PUCCIARELLI, Alfredo, 2004, op. cit, p. 113-114.

40 REDICK, op. cit., 1995, p. 19.

41 CASTRO MADERO, Carlos y TAKACS, Esteban. Política nuclear argentina. ¿Avance o retroceso? Buenos Aires: El Ateneo, 1991. p. 59-60.

42 CASTRO MADERO, Carlos, 1978, op. cit., p. 37.

43 BENJAMIN, Milton. Argentina on Threshold Of Nuclear Reprocessing. Washington Post. Octubre 16, A1, A21, 1978.

44 CASTRO MADERO, Carlos y TAKACS, Esteban, op. cit., 1991, p. 102.

45 CASTRO MADERO, Carlos y TAKACS, 1991, op. cit., 1991, p. 84-85.

46 CASALET, María. Recursos humanos de investigación en el Complejo Científico y tecnológico: evolución del empleo y políticas de recursos humanos del CONICET. En OTEIZA, Enrique (Org.). La política de investigación científica y tecnológica argentina. Historia y perspectivas. pp. 235-246. Buenos Aires: CEAL, 1992.

47 Decreto-ley 1291/58.

48 OTEIZA, Enrique (Comp.). La política de investigación científica y tecnológica argentina. Historia y perspectivas. Buenos Aires: CEAL, 1992.

49 OTEIZA, 1992, op. cit., 1992, p. 32.

50 CASALET, 1992, op. cit., p. 242.

51 FELD, Adriana. El CONICET: radicalización, represión y cambios institucionales durante las décadas de 1960 y 1970". En GÁRGANO, Cecilia (Comp.) Ciencia en Dictadura. Trayectorias, agendas de investigación y políticas represivas en Argentina. Buenos Aires: Ediciones INTA, 2015. p.57.

52 CONICET. Informe sobre investigaciones de hechos ocurridos en el CONICET. Período 1976-1983. Buenos Aires: CONICET. 1989, p. 67, citado en RODRíGUEZ, Laura. Las ciencias sociales durante la última dictadura: agendas, investigadores e instituciones". En GÁRGANO, Cecilia (Comp.). Ciencia en Dictadura. Trayectorias, agendas de investigación y políticas represivas en Argentina. Buenos Aires: Ediciones INTA, 2015. p. 23.

53 ADLER, op. cit., 1987, p. 157.

54 SARAIVA, Tiago y WISE, Norton. Autarky/Autarchy: Genetics, Food Production and the Building of Fascism. Historical Studies in the Natural Sciences. 40 , 4, p. 419-428, 2010. p. 426.

[Artigo recebido em Julho de 2018. Aceito para publicação em Setembro de 2018] 